\title{
Ni pu tremen. Mis antepasados de Paula González Seguel: Repertorios de prácticas escénicas y diferencia cultural ${ }^{*}$
}

\author{
Ni pu tremen. My ancestors by Paula González Seguel: \\ Repertoires of scenic practices and cultural differences
}

Patricia Henríquez Puentes ${ }^{* *}$, Mauricio Ostria González ${ }^{* * *}$

\begin{abstract}
RESUMEN
Los lenguajes de la visualidad, la música, las danzas, los cantos, los textiles y sus iconografías, así como de la orfebrería en plata que se encuentran tramados en la obra Ni pu tremen. Mis antepasados de Paula González Seguel, hacen visibles, audibles y sensorialmente perceptibles la densidad de la diferencia cultural mapuche. Esta propuesta, representativa de la dramaturgia mapuche actual, pone énfasis en la cultura corporizada y en una diversidad de formas de conocimiento, almacenamiento y transmisión cultural, ampliando el canon y las fronteras disciplinarias. En la obra, un repertorio de prácticas escénicas y soportes mnemónicos irrumpen en el archivo para escenificar uno de los asuntos irresueltos más sentidos para el pueblo mapuche: su identidad territorial.
\end{abstract}

\section{SUMMARY}

The languages of visuality, music, dance, song, textiles and their iconography, as well as silverwork are woven into the theatrical work Ñi pu tremen. My ancestors by Paula González Seguel, makes the density of Mapuche cultural differences visible, audible and sensorily perceptible. This theatrical idea is representative of current Mapuche dramaturgy. It emphasizes embodied culture and does so using a diversity of forms of cultural
Palabras clave:

mapuche, dramaturgia, diferencia cultural, repertorio.
Keywords:

Mapuche, dramaturgy, cultural difference, repertoire.

\footnotetext{
* Este artículo se inscribe en el marco del proyecto "El repertorio en un corpus de dramaturgia mapuche", VRID Multidisciplinario de la Universidad de Concepción No 124/20. (2020-2022).

** Chilena. Doctora en Literatura Latinoamericana de la Universidad de Concepción. Académica de la Universidad de Concepción, Concepción, Chile. pathenriquez@udec.cl *** Chileno. Profesor Emérito de la Universidad de Concepción. Académico de la Universidad de Concepción, Concepción, Chile.mostria@udec.cl
} 
Ñi pu tremen. Mis antepasados de Paula González Seguel | Henríquez y Ostria

knowledge, memory and transmission, expanding the canon and disciplinary boundaries. In the play, a repertoire of scenic practices and mnemonic devices break into the archive to stage one of the biggest unresolved issues for Mapuche people: their territorial identity. 


\section{Introducción}

Los repertorios latinoamericanos de prácticas escénicas de raíz indígena como formas de conocimiento, almacenamiento y transmisión cultural, definen anualmente los ciclos festivos de las comunidades de origen. Su despliegue genera una especie de suspensión temporal en la que, entre otras cosas, se subvierte el uso de los espacios públicos y privados, al mismo tiempo que se refuerza el pensamiento colectivo y el saber localizado a través de procesos de cognición corporizada (Taylor 18). En esta escena, las artes impregnan todas las acciones de la comunidad, instaurando una nueva realidad como resultado del predominio de los lenguajes de la danza, la música, la poesía y la visualidad que inunda calles, plazas y avenidas de un nuevo ritmo sonoro y performativo y de un compendio de formas y colores significativos que conducen a los participantes a una "manera diferente de conocer y ser en el mundo" (Taylor 18). Así, la performatividad festiva reinventa cíclicamente pueblos y ciudades, "desde la perspectiva de una subjetividad inserta en un contexto corporal, social y cultural” (Guerra 302).

Estos repertorios, verdaderos soportes de "memoria encapsulada de lo vivido, experimentado y conocido a través de los sentidos" (Phelan 2), no solo han impregnado cíclicamente y desde tiempos ancestrales la tridimensionalidad del espacio comunitario, exhibiendo, recreando y transmitiendo diferencias culturales a través de los lenguajes de las artes, sino que también han tenido presencia en el archivo, pese a que desde allí fueron tempranamente expulsados. Los antecedentes de este proceso datan del siglo XVII. Ejemplo de ello es el texto Primer Nueva Crónica y Buen Gobierno (1615) de Felipe Guamán Poma de Ayala, texto en el que las formas no alfabéticas del discurso andino ofrecen hasta el día de hoy "interacciones complejas entre tradición oral, visualidad, cultura material, arte y escritura" (Catelli 1). Lo propio ocurre con una de las obras emblemáticas de la tradición escénica latinoamericana, el Rabinal Aquí o Danza del Tun, obra maya achí que data aproximadamente del siglo XIII d. C., cuyas versiones en escritura (siglo XIX), dejan ver en sus intersticios marcas de repertorios reveladores de una memoria cultural escénica (Henríquez 2).

Los repertorios escénicos mapuche tienen larga data. Su estudio, sin embargo, aún es incipiente, pese a su constante presencia en la escena ritual, política y artística contemporánea. Ha sido recurrente, 
en el marco de los recientes estudios acerca de teatro y dramaturgia mapuche, que se identifique a la figura de Manuel Aburto Panguilef (1887-1952), fundador en 1916 de la Compañía Dramática Araucana Llufquehuenu ${ }^{1}$, como su más antiguo exponente. Los escasos documentos al respecto señalan que uno de los aspectos más relevantes de esta iniciativa fue su proyecto de autorrepresentación urbana. Sin embargo, no lo es menos que, junto con irrumpir en la escena citadina de la época y disputar los "sistemas de organización propios de la ciudad" (Gutiérrez 195), anticipara en casi cien años la reflexión respecto de la importancia de las prácticas de memoria corporizadas mapuche para la mantención-transformación de conocimiento. Es muy probable que en esa época su propuesta no haya sido comprendida, sino como propia de los "géneros de entretención que en el fondo muestran la general tendencia humana a expresarse en un diálogo colectivo" (Pereira Salas 13), o bien, como una "exhibición de ritos, costumbres y deportes de la raza" (Pradenas 248), de escaso valor escénico para un espectador vinculado con "los sectores productores de objetos culturales, en este caso, los discursos teatrales" (Villegas 29-30). Por otra parte, es posible pensar que la propuesta visual de la Compañía Dramática Araucana se apartó de aquella que conformaba el "discurso visual de la cultura legitimada, la competencia visual de los productores y espectadores, y los agentes formadores de esa competencia" (Villegas 32). Lo cierto es que este proyecto no solo constituye el primer antecedente del que se ha tenido noticia, hasta el día de hoy, de la fundación de una compañía teatral mapuche, sino también el primer antecedente de la puesta en funcionamiento, en la actual zona de la frontera, de una estrategia de resistencia utilizada desde el siglo XVI por los pueblos indígenas de los antiguos Anahuac y Tahuantinsuyu. Esto es la escenificación de un repertorio de prácticas escénicas en la que lo fundamental ha sido mostrar el sentido profundo y radical de su diferencia y no precisamente su "diversidad" que, tal como lo afirma

1 Luis Pradenas (2009) afirma que Manuel Aburto Panguilef funda el Conjunto Artístico Mapuche Llufquehuenu, también denominado Compañía Dramática Araucana en 1916, siendo considerado el dirigente mapuche más importante de la primera mitad del siglo XX. Según Menard (11) el quehacer de la compañía estuvo directamente relacionado con los lineamientos políticos de su fundador, especialmente con aquellos que demandaban la devolución de las tierras indígenas, lo que entre otras cosas implicaba el ejercicio de sus roles sociales. 
Segato, se plantea como mera variedad de rótulos o logos de identidad destinados al reclamo por inclusión a un mundo asentado sobre premisas y valores ya constituidos e incontestables" (17).

Las prácticas escénicas de tradición indígena que se escenifican anualmente en los lugares de origen proponen una meta y una perspectiva diferentes respecto de los "principios estructuradores de (la civilización y de la cultura)" (Mazzotti y Zeballos Aguilar 3). Entre otras cosas, proponen "dislocar la visión... y al mismo tiempo rectificar el pensamiento mismo" (Didi-Huberman 41) para poner atención en la cultura corporizada, lo que supone "ampliar el canon... y las fronteras disciplinarias tradicionales para incluir prácticas previamente dejadas fuera de su ámbito de competencia" (Taylor 52). Es decir, para construir conocimiento a partir de su propia cultura.

La compañía se fundó en 1916, nueve años después de la celebración de último Parlamento ${ }^{2}$, escena que marcó el progresivo proceso de exclusión, agresión y expropiación de las tierras mapuche. Desde ese entonces, hasta la década de 1980, las prácticas escénicas mantuvieron su relevancia sobre todo en escenarios rituales. Con posterioridad, las relaciones entre estas prácticas y los procesos de surgimiento, desarrollo y consolidación de movimientos de reivindicación política mapuche ${ }^{3}$ cobraron gran relevancia, inaugurando el desarrollo de la dramaturgia mapuche.

El año 1981 se funda el Grupo de Teatro Mapuche ${ }^{4}$, cuyas propuestas se escenifican en la zona rural de la IX Región de La Araucanía, específicamente, en los alrededores de la ciudad de Temuco, "Aunque

2 El último parlamento mapuche se celebró en Coz Coz, provincia de Panguipulli, en 1907. El objetivo del parlamento fue reunir a los caciques, de un radio cercano a sesenta u ochenta leguas de Coz-Coz, para "referirse mutuamente los infortunios que padecen; contarse en familia los inauditos atropellos que los "españoles" cometen contra ellos.. y resolver de mancomún lo que sería conveniente hacer...” (Díaz Meza 16-17)

3 Los Centros Culturales Mapuche de Chile, conocidos posteriormente como Ad Mapu (1978), constituyen la primera organización mapuche originada en.Chile en tiempos de la dictadura. El Ad Mapu retoma el legado de las organizaciones mapuche existentes hasta 1973 en su demanda por la restitución de tierras y la defensa de la comunidad y la cultura, el lenguaje, las costumbres, los ritos, las creencias y el arte como elementos que conforman a la Sociedad Mapuche (Levil 233-236).

4 El Grupo de Teatro Mapuche (1981), estaba integrado por Diva Millapán, Virginia Calvillán, Domingo Carilao, Ramón Chanqueo, Marihueño Huilcamán, Nancy Manqueñir, Carmen Pichicona, Juan Tragolaf, Pedro Neculqueo y Domingo Colicoy, quien se desempeñaba como coordinador. (Martínez 603). El año 1987 la Revista Cauce informó 
se han presentado en las principales ciudades entre Santiago y Chiloé y fueron invitados al Primer Encuentro Internacional de Teatro Popular en Neuquén, el trabajo del grupo está dirigido principalmente a las comunidades mapuche rurales" (González, E. 31). El año 1987, el elenco, dirigido en su inicio por Armando Marileo y posteriormente por Domingo Colicoy, había escenificado 18 obras de creación colectiva, en las que se enfatizaba la influencia de la tradición narrativa mapuche a través de los epew (cuentos) y de los konew (adivinanzas), como también de los ülkantun (canciones) acompañados del sonido de instrumentos musicales como la trutruka, la pifüllka, el kultrung y el trompe. Algunas de las obras figuran mencionadas en la Revista Cauce del año 1987: Petü Mülekalu (Los que van quedando), "obra que cuenta la historia de los comienzos de la guerra de Arauco y el choque cultural desde la mirada mapuche" (González, E. 31); Ñuke Мари (Madre Tierra), obra que aborda el problema del "desarraigo de los emigrantes mapuches y de la identidad cultural perdida en las ciudades" (31); Mellipilún (Cuatro orejas), obra de temática infantil "basada en un epew que cuenta la historia de la astucia de un zorro empeñado en engañar a dos conejos" (31); Püram Kachilla (Cosecha de trigo), cuya historia al parecer enfatiza en situaciones de la vida cotidiana mapuche.

\section{La obra}

Ñi pu tremen. Mis antepasados ${ }^{5}$ de Paula González Seguel es dramaturgia mapuche publicada recientemente en el marco del proyecto editorial Dramaturgias de la resistencia. Teatro documental, Kimvn marry xipan (2018), texto que reúne parte de la producción dramática de dos actrices, directoras y dramaturgas: Paula González Seguel, quien también oficia de compiladora y Marisol Vega Medina. Cuatro son las obras que integran esta compilación: Galvarino de Marisol Vega Medina; Ni pu tremen. Mis antepasados; Territorio descuajado. Testimonio de un país mestizo; y Nuke. Una mirada íntima hacia la resistencia ma-

que el elenco había recibido asesoría de la Escuela de Teatro de la Universidad Católica. (González, E. 31).

5 Ni pu tremen. Mis antepasados obtuvo el premio Eugenio Guzmán a la Mejor Dirección por la Universidad de Chile (2009), Premio Apes por Mejor Dramaturgia (2009). Ha participado del Festival Internacional de Santiago a Mil 2010, de Les Translatines y Sens interdits en Bayone y Lyon, Francia (2011). 
puche, reescritura de la obra Ñuke de David Arancibia Urzúa, las tres de Paula González Seguel.

Ni pu tremen. Mis antepasados es teatro documental. En palabras de Evelyn González Seguel, cofundadora y directora musical de la Compañía Kimvn Teatro, esta obra fue el resultado del "vínculo humano y artístico con mujeres de la asociación mapuche urbana Petu Moguelein Mawidache (Aún estamos vivos la gente del bosque), con quienes las integrantes de la compañía se reunieron durante un año para recopilar testimonios del "complejo proceso de migración campo/ciudad donde fueron violentamente discriminadas" (18).

La obra incluye la participación de once mujeres, no actrices, desarraigadas de sus lugares de origen y arraigadas, en el presente de la propuesta, en Santiago: Elena Mercado Marileo, Carmen Saihueque, Juana Huaquilaf, Marisol Ancamil, María Huaquipan, Maribel Hueche, Norma Nahuel, María Seguel Mercado, Elsa Quinchaleo, Isolina Mercado Marileo y Aurelia Huina, "la más adulta de las lamnien" (González, P. 41). Junto con ellas, también participan tres jóvenes: Constanza Hueche, Norma Hueche y Marlén Hueche, "quienes deben tener entre 11 y 14 años" (González, P. 41).

En Ni pu tremen. Mis antepasados estas once mujeres narran frente a los espectadores una selección de "vivencias reales... para visibilizar y dar cuenta desde el testimonio... las diversas problemáticas sociales, culturales y políticas [a las] que [se] ha visto enfrentado el pueblo mapuche: el despojo territorial, la pobreza, la marginalidad y la violencia histórica" (González, P. 41). Desde este punto de vista, se trata de una obra basada en vivencias singulares de lo social. Los relatos, en español - con pasajes en mapuzungun-, se ordenan de acuerdo con dos motivos: la infancia vivida y recordada como fuente primigenia de felicidad y la adultez como fuente de desarraigo, pero también como posibilidad de resistencia. El recuerdo de ambas escenas, introducido a través de una pregunta de Norma Nahuel, una de estas once mujeres, trae al presente de la escenificación del espacio rural y el urbano, "identificados durante el siglo XX, en América Latina, como dos polos contrapuestos" (Mansilla e Imilán 2). En la obra, el primero de ellos se asocia con la infancia vivenciada y sus imágenes y símbolos, específicamente en la zona de la Araucanía, y con una selección de espacios significativos enunciados para para es- 
tas mujeres. Chol $\mathrm{Chol}^{6}$ (lugar de cardos), Rañin Tuleufu ${ }^{7}$, Padre las Casas, Mulcochureo, Lautaro y Temuco. Por otra parte, el espacio de la adultez corresponde a los suburbios de Santiago, donde se inicia la vida laboral y familiar y, al mismo tiempo, donde se experimenta la discriminación y la violencia que, en este caso, es doble y acumulativa: étnica y política.

Me acuerdo que cuando yo era niña, mi abuela paterna no me quería..., porque decía que yo era la hija de la india... (González, P. 45)

Yo siempre fui discriminao,' siempre fui maltratao,' pero siempre yo me defendí... Después cuando llegué a Santiago... trabajé, me trataron mal, me dijeron india despatriá... (González, P. 46-47)

nosotros estamos jugando con mis primos y cuando sentimos bulla de vehículo... uuhhh... os pacos, los pacos!!! Y salieron arrancando mis primos para un la'o y nosotros... y yo y mi mamá sola y yo entonces... y yo... ¡Mi mamá, mi mamá, mi mamá!, sentí unos disparos, disparos, disparos, le empezaron a disparar a mis primos y corrían por entremedio del bosque, pero eran como delincuentes... Y me acuerdo que yo llegando a la casa.... Iba un militar arrastrando a mi mamá del pelo y yo como niña fui a defender a mi mamá... Me recuerdo que nos sentaron en un banco que tenía mi papá. Que trabajaba en carpintería... estaba yo y mis dos otros hermanos, yo era la menor y empezaron a apuntarnos con la escopeta, mientras a mi mamá le disparaban por el otro lao y entonces eso jue como... No sé, eso es lo que más duele, porque yo vi que le estaban disparando a ella y le disparaban a ambos lados de los oídos... (González, P. 51-52).

6 Chol Chol o Cholchol es una comuna de la provincia de Cautín, integrada por un $70 \%$ de población mapuche. Según Ruiz (2003), esta comuna formó parte del territorio histórico mapuche (wallmapu), específicamente del Butalmapu Nagche de las tierras bajas de la IX Región de La Araucanía. En este sentido, los habitantes de la actual comuna de Chol Chol corresponden a aquellos pertenecientes a la identidad territorial de las tierras bajas (22-23).

7 En Rañin Tuleufu o Ranguituleufu, el 25 de diciembre de 1931 se realizó el IX Congreso Araucano, en el que Manuel Aburto Panguilef propuso la fundación de una República Indígena, "la más sentida aspiración de la raza (para que) pueda desenvolver su vida de acuerdo a su psicología, costumbres y rituales" (Aburto Panguilef 2013). 


\section{Los procedimientos}

$\tilde{N} i$ pu tremen. Mis antepasados se caracteriza por la presencia constante de una diversa y rica selección de "actos corporizados (que) generan, registran y transmiten conocimiento" (Taylor 57), junto a los cuales cobra especial relevancia una serie de documentos materiales, rituales y simbólicos. Ejemplo de ello es la presencia de algunos tipos especiales de documentos de uso cotidiano y ritual como la orfebrería mapuche ${ }^{8}$, que en la obra se encuentra materializada en piezas de plata de alto simbolismo como la xapelacucha ${ }^{9}$ y el xarilonco ${ }^{10}$; y en textiles ${ }^{11}$ como el kvpam y el xarihue ${ }^{12}$. De igual modo, ocupa un lugar de importancia fundamental la inclusión de la danza del purun ${ }^{13}$, la

8 La sacralidad de estas piezas estaba relacionada con el contenido informativo y simbolismo del metal "la plata, lien, nacida de las lágrimas de la luna, kuyen, y considerada como un animal luminoso, protector y sanador que aporta sabiduría y fertilidad a quien lo lleva puesto" (Núñez-Regueiro y Guerra 2).

9 La xapelacucha o trapelakucha forma parte de la platería mapuche cuyos diseños, en las líneas, en los trazos y signos inscritos en las planchas de plata, muestran la impronta cultural de este pueblo indígena. Entre los motivos de carácter ornamental utilizados por los plateros araucanos para incorporarlos a las joyas destacan las representaciones figurativas zoomorfas, estilizaciones simples, de aves, serpientes, figuras y caras humanas (Morris Von Bennewitz y Guedda 51, 55).

10 El xarilonco o trarilonco forma parte del grupo de joyas de casquetes de plata, según la categorización propuesta por Morris Von Bennewitz y Guedda (69). La característica de esta variedad de joyas es que están confeccionadas con pequeños casquetes de plata cosidos, mediante un hilado invisible, en la superficie de fajas de lana o cuero sobado... Los adornos más importantes en los que se han empleado estos casquetes de plata son las prendas destinadas a adornar la cabeza y la cabellera (Morris Von Bennewitz y Guedda 83).

11 Arnold (2016) concibe el textil como un artefacto en elaboración que a veces incorpora múltiples componentes en su producción, cada uno de ellos elaborado a su vez por medio de distintos procesos, desde su estado inicial como recurso natural, vía las transformaciones en la materia prima, y solo después por los procesos de elaboración textil. Es decir, Arnold se aparta de la tendencia a percibir el textil como un objeto terminado y ya socializado en el mundo, lo concibe como un documento (Arnold 19).

12 Trariwe, del mapudungun trarün "llevar atado, amarrado" y we, sufijo sustantivador que significa "lugar" y se utiliza para ceñir la vestimenta a la cintura, otorgando especial firmeza para las exigentes labores hogareñas y de labranza, embarazo y crianza (Chacana 2). Todo trariwe posee dos bordes opuestos (paralelamente invertidos) de idénticas características que requieren de una doble lectura: vertical y horizontal. El trariwe es, un recipiente semántico de gran amplitud e importancia en el marco de la estética mapuche (Mege 89-108).

13 En lo que concierne a las danzas mapuche, Memoria Chilena (s/p) identifica las siguientes: Marra Purum (Danza de la liebre), Wemul Purun (Danza del ciervo), Rere Purun (Danza del pájaro carpintero) y Choike Purun (Danza del Ñandú). Las coreografías de cada una de las danzas son distintas. Así también, hay algunos estilos que son más frecuentes o populares, como por ejemplo el choique purun o "danza del ñandú", de 
narración de leyendas ${ }^{14}$ y la entonación del eyutun, en diálogo con los versos y sones del Gniyatun de Violeta Parra. El repertorio de documentos de lo vivido, experimentado y conocido que se encuentra en este archivo dramático, reafirmando el "efecto de indiscernibilidad" (Alvarado 137-151) de la vestimenta, joyas y actos, es coherente con el carácter documental del mismo.

En Ni pu tremen. Mis antepasados el mundo creado establece una relación de correspondencia directa con el mundo real, desestabilizando con ello las certezas del espectador respecto de las fronteras entre ciertos conceptos dicotómicos como arte/vida, realidad/ficción, público/privado. Aquí, a través de mecanismos referenciales, el espectador es instalado en una zona de inestabilidad, ambigüedad y transitoriedad propia del resultado de una percepción oscilante entre la apreciación del cuerpo del actor/actriz y su remisión a un personaje (Fischer-Lichte 181, 346). En esta obra el diálogo no es el componente exclusivo del tejido dramático. Así, la condición absoluta del drama se resquebraja al incluir teatro dentro del teatro y al idear un escenario circular que establece transiciones permanentes hacia los espectadores, por lo tanto, que se aparta del escenario a la italiana o de caja prismática; como también al hacer visible la relación existente entre el actor y el papel que este desempeña (Szondi 73-77). Tal como lo afirma Sarrazac (32), en relación con las dramaturgias de las últimas décadas, aquí predomina una forma dramática más libre que obliga a preguntarse por las fronteras entre poesía, narrativa, drama o ensayo; y que cuestiona los procedimientos de ese "teatro realista psicológico que desde el siglo XVIII defendía que el espectador debía percibir el cuerpo del actor únicamente como cuerpo del personaje... (para jugar más bien con) la multiestabilidad perceptiva" (FischerLichte 182).

carácter recreativo realizado en fiestas y rituales; o el kollón purun o "danza del enmascarado".

14 El epewtufe (narrador de epew) y el ayekafe (narrador comediante) - quienes cultivan habilidades histriónicas y escénicas a lo largo de sus vidas-, desarrollan el relato utilizando distintas voces y gestualidades de acuerdo a las características físicas, éticas y sicológicas de los personajes presentes en la narración. Igualmente, para dar color e intensidad a la puesta en escena, imitan los lenguajes del mundo natural acudiendo al uso reiterado de onomatopeyas (Huenún 9). 


\section{La ruka y el cuerpo confesión}

Ni pu tremen. Mis antepasados tiene lugar en una ruka, "unidad habitacional de la comunidad mapuche, reflejando el alcance de la técnica que se inserta en un ámbito natural" (Zelada y Espósito 76) que esta propuesta explora y pone a prueba en sus potencialidades escénicas, lo que no significa la anulación de sus posibilidades de significación, de acuerdo a su función original. Aquí, tal como lo advierte Fischer-Lichte, en relación con los procedimientos con los que en los años sesenta se intensificaba la performatividad del espacio, percepción, asociación, recuerdo e imaginación se solapan (231) la ruka se experimenta simultáneamente como imaginada y como recordada. Es la superposición del espacio real e imaginario la que origina la espacialidad en esta obra. Desde el punto de vista de McAuley, la "naturaleza transitoria del acontecimiento teatral" (76) entra en relación con la ruka, espacio culturalmente complejo al que es precisamente invitado a ingresar el espectador para ser sumergido en su atmósfera particular. En este sentido, provisto de un solo vano, la puerta de ingreso orientada hacia el Puel Mapu, por donde desde la mañana ingresan los primeros rayos de sol, energizando su interior y a sus moradores.

La ruka, más allá de una casa, es un acto colectivo ... el término está asociado a nido, como en rukamanke (nido de cóndor), o rukanawe (nido de tigre). En su dimensión espacial, sintetiza tecnología, materialidad, relaciones espaciales, funciones y usos representativos de la comunidad... El proceso constructivo refleja un sentido de adaptabilidad funcional a las condiciones climáticas y geográficas específicas (ya sea en el valle central, la costa o la cordillera), como entendimiento del hombre con la naturaleza, valorizando los materiales que se entregan a la técnica. (Zelada y Espósito, 70)

Es precisamente en este espacio que once mujeres de la comunidad mapuche Petu Moguelein Mawidache y del Club de adultas mayores Flor de Invierno, ambos de la comuna El Bosque de Santiago de Chile, dan testimonio de sí mismas, ante los espectadores que rodean el fogón, eje articulador de la vida social mapuche, sitio del calor físico y humano, de las relaciones interpersonales, familiares y fraternales; fundamental para proveer de iluminación durante las noches y para cocinar; y donde tradicionalmente "se desarrolla el lenguaje y 
se elaboran imágenes mentales que refuerzan la cultura" (Zelada y Espósito 70).

MARISOL ANCAMIL: Yo, siendo hija de padres campesinos, mi niñez fue en el campo. Mi papá se levantaba muy temprano, encendía el fuego en la cocina... y eso yo lo notaba porque el olor a humo se sentía por toda la casa, luego tomaba su mate amargo, después enyugaba los bueyes y salía a arar la tierra...

ELENA MERCADO MARILEO: Yo cuando fui chica mi recuerdo más lindo que tengo es que era mala, era muy hiperquinética. Mis papás tenían muchos animales y nosotras con mi hermana, la Juanita, éramos muy maldadosas. Salíamos a jugar con los chanchos y montábamos nuestra chancha preferida...llevábamos nuestro cocaví, tortilla y nos íbamos a cuidar los chanchos al río, nos juntábamos con otros niños, niñas y hombres...Nosotras éramos las patronas, porque mandábamos a los mapuchitos...

MARÍA HUAIQUIPÁN: Mi recuerdo más bonito fue cuando tenía más o menos siete años, esto fue en un colegio de campo, llamado Rañin Tuleufu, que significa entre ríos en mapuzungun. Yo vi llegar un camión cargado con juguetes, que venían en bolsas transparentes, venían pelotas de todos los colores y los pusieron en una sala. Después nos dijeron, hagan una fila, tomen distancia y nos fueron llamando uno por uno... en una de esas me tocó a mí, y me regalaron una muñeca... linda (pausa). (González, P. 43-44)

Once voces ponen en escena uno de los tópicos escasamente abordados por los estudios teatrales, el de la autobiografía escénica que, tal como afirma Trastoy (2008), hace ostensible su carácter referencial “ya que hace del propio pasado su temática básica y pone especial énfasis en el balance y justificación de aquellos acontecimientos que marcaron transformaciones radicales en la vida del narrador" (1). En Ni $i u$ tremen. Mis antepasados estas historias buscan reconstruir/recuperar territorialmente las identidades mapuche, generando sentido de pertenencia respecto del territorio, de los antepasados, de los valores comunitarios y las maneras de vivir y ver. Estas historias recuerdan los cantos genealógicos de las culturas africanas (Fall 104) pues suponen, al igual que aquellos, una lectura de la lógica de las generaciones mapuche en sus comunidades y luego, en el tránsito desde estas a la ciu- 
dad, especialmente a Santiago. Ambos relatos "nos recuerdan cómo la pérdida adquiere significando y genera recuperación, no solo del objeto y para el objeto, sino para el que recuerda" (Pelhan 1). Se acortan distancias en el tiempo y el espacio entre la vida actual de cada una de estas mujeres que experimentaron el desarraigo y su pasado.

Lo particular de esta autobiografía escénica radica en que aquí se traslapa el objetivo de crear una ilusión de máxima fidelidad con la autenticidad de estas mujeres no actrices que enuncian discursos en torno a un fogón. En paralelo, junto con la presentación de una selección de relatos que se convierten en confesiones de fragmentos de sus historias de vida y de peculiares formas de habitar el espacio urbano, es decir, de vivir la experiencia Warriache ${ }^{15}$ o de vivir la experiencia Mapurbe, en palabras de Aniñir (2009), enuncian con "sus cuerpos en los que se encuentra escrita la experiencia cuando esta aún no ha sido contada" (Cornago 4).

Tal como lo dice Cornago (2019), los rasgos físicos son los que convierten al testigo en una joya preciada del discurso contemporáneo acerca de la verdad personal o colectiva, la verdad de la historia. El aura que rodea al testigo no se apoya en su capacidad de contar lo que vio, sufrió o experimentó, sino en la propia presencia de un cuerpo en su particular materialidad que vio eso, lo sufrió o lo experimentó (4). Estos cuerpos sitúan al espectador en una situación de intersticialidad como resultado de la oscilación entre la focalización en el cuerpo del no actor y en el cuerpo del personaje y viceversa. Aquí el personaje aparentemente desaparece. En este sentido, la propuesta de la dramaturga se aparta de las teorías estéticas tradicionales, resistiéndose a la lectura del cuerpo de las mujeres como "mero portador de significado, sino que se centra en la materialidad específica del cuerpo y del espacio" (Fischer-Lichte 68), piezas claves de la realización escénica. Aquí, estas once mujeres no "interpretan" una realidad, sino que la experimentan nuevamente a través del ejercicio escénico de traer a la memoria el recuerdo y volver a vivir sus efectos, volver a pasar por el corazón, por los gestos y movimientos. Así, el cuerpo deja de ser pre-

15 En Santiago reside un segmento masivo de población mapuche contemporánea que, a través de sus prácticas de habitar, experimenta y desarrolla de forma cotidiana mecanismos y estrategias de apropiación del espacio urbano. Esta experiencia es denominada por Imilán (2014) como lo Warriache. 
sencia evocada para pasar a ser experiencia de contexto. En este sentido, propositivo de una necesidad de integración entre quienes han permanecido dispersos geográficamente y separados territorialmente. Tal como lo plantea Levil "La integración del Puel Mapu y del Gulu Мари constituye una integración tanto del territorio como de la población, lo cual constituiría, ni más ni menos que la revalidación de una dinámica interrumpida a fines del siglo XIX, con la invasión de los ejércitos chileno y argentino y el fin de la vida fronteriza" (247). En esta obra lo que se propone es un acontecimiento único e irrepetible en el que todos los presentes se vean involucrados en un proceso de dislocación conducente a reconocer la necesidad de esa "integración hacia adentro" (Levil 247). El espectador, frente al testigo, escucha ese cuerpo-historia convertido en palabra, encarnando el verbo, una vieja utopía escénica y política (Cornago 25).

A la enunciación de testimonios y a los cuerpos-confesión se agrega una serie de actos en los que el espectador toma parte "por medio de una percepción que no realiza solo el ojo o el oído, sino también el sentido corporal, pues el cuerpo entero (lo realiza) de manera sinestésica" (Fischer-Lichte 73). Aquí las mujeres hilan, toman mate y comen sopaipillas, mientras se escucha música mexicana, y se acompaña con palmas a quienes bailan la cueca "Para qué me casaría" de Violeta Parra, se ve danzar un purun, interpretar un eyutun, canto de la Machi que, acompañado de trompe y guitarra, genera una espacialidad tal, como resultado de la sonoridad, que permite celebrar una rogativa hacia donde sale el sol, hacia el puel mapu. La obra, en este sentido, deviene en ritual, por lo tanto, se enmarca en una atmósfera de olores especiales, como el que provoca el fogón, la paja de la ruka y la preparación de comida; de una iluminación particular, como aquella que permite el único vano de la ruka, la puerta; del poder de la palabra en mapudungun que enuncia oraciones; del movimiento del cuerpo a través de las danzas y de sonidos a través de la música que propone un espacio sonoro mapuche.

Tal como lo advierte Fischer-Lichte, la sonoridad genera siempre espacialidad. La vocalidad, además, produce siempre corporalidad. Con y en la voz se originan los tres tipos de materialidad: la corporal, la espacial y la sonora. Sonidos y olores envuelven el cuerpo de los espectadores, la atmósfera se adentra en el cuerpo del espectador y lo 
abre para ella (242). En Ni pu tremen. Mis antepasados el espectador se ve envuelto en un concierto de sonidos, olores y visualidades para participar de la escena y reaccionar no solo a las invitaciones de quienes "llevan la realización escénica" (74), sino también al comportamiento de los otros espectadores que junto a él la rodean. La obra se cierra con una ceremonia ritual al son de la interpretación de cuatro estrofas del Guillatún de Violeta Parra, en voz de tres niñas mapuche cuyas edades fluctúan entre los 11 y 14 años, las mismas que anteriormente han danzado el purun, representando a las nuevas generaciones en las que depositan "los hilos de tramas históricas por algún tiempo abandonadas (Segato 19). El apagón que indica el fin de la obra es antecedido por la imagen de la menor de las niñas que levanta la wenufoye, la bandera nacional mapuche, el ícono clave y principal de la simbología mapuche de los últimos tiempos, símbolo de la reconstrucción nacional indígena anticolonial (Ancán 287-288).

\section{Conclusiones}

Ni pu tremen. Mis antepasados es dramaturgia mapuche que contiene un repertorio de prácticas escénicas y de documentos de alto valor simbólico ritual que conducen al espectador-lector a dislocar la visión y el pensamiento respecto de la cultura mapuche, para aproximarse al sentido profundo y radical de su diferencia.

Esta propuesta, inscrita en el marco del teatro documento, instala en escena a once mujeres no actrices, quienes hacen de su pasado la temática de la obra, generando sentido de pertenencia respecto del territorio, de los antepasados, de los valores comunitarios y las maneras de vivir y ver. De esta manera, a través de la autobiografía escénica, estos cuerpos-confesión, en los que se encuentra escrita la experiencia cuando aún no ha sido contada, dan testimonio de sí mismos, recordando a los espectadores el sentido de la pérdida de la identidad y sus posibilidades de recuperación.

La obra ha sido concebida para que tenga lugar en una ruka, espacio culturalmente complejo, al que es invitado a ingresar el espectador para experimentarlo simultáneamente como imaginado y recordado. La escenificación de la obra no anula las posibilidades de significación de la ruka, de acuerdo con su función original, sino que intensifica su performatividad espacial para superponer lo real y lo imaginario. 


\section{Referencias bibliográficas}

Aburto Panguilef, Manuel. Libro Diario del Presidente de la federación Araucana. 1940, 1942, 1948-1951. Ed. André Menard. Santiago de Chile, Colibris, 2013.

Alvarado, Margarita. "Indian fashion. La imagen dislocada del indio chileno". Estudios Atacameños, no. 20, 2000, pp. 137-151.

Ancán, José. “A 25 años de la wenufoye. Una breve genealogía de la bandera nacional mapuche". Revista Anales, no. 1, 2017, pp. 283-305. Recuperado de https://enfoqueseducacionales. uchile.cl/index.php/ANUC/article/download/49007/51480. 17 de marzo de 2020.

Aniñir, David. Mapurbe/Venganza a raíz. Santiago, Pehuén ediciones, 2009. Impreso.

Arnold, Denisse. El textil y la documentación del tributo en Los Andes: Los significados del tejido en contextos tributarios. La Paz, IILCA, Serie Etnografías No 5, 2016. Impreso.

Catelli, Laura. "Uso de la écfrasis en la Nueva corónica y buen gobierno (1615) de Felipe Guamán Poma de Ayala". Interrelaciones entre literatura y artes. América y Europa en las épocas Moderna y Contemporánea. Dir. Ana Lía Gabrieloni. Buenos Aires, Editorial UNRN, 2018, pp. 21-53. Impreso.

Cornago, Oscar. “Actuar 'de verdad. La confesión como estrategia escénica". Artea, 2019. Recuperado de http://archivoartea.uclm. es/wp-content/uploads/2019/04/Oscar-Cornago-La-confesion-como-estrategia-escenica-1.pdf

Chacana Hidalgo, Susana. “Trariwe de machi: investigación y documentación". Colecciones Digitales, Subdirección de Investigación Dibam. 2017. Recuperado de http://www.museoregionalaraucania.cl/642/w3-article-83074.html

Didi-Huberman, Georges. “La emoción no dice 'yo'. Diez fragmentos sobre la libertad estética”. Alfredo Jaar. La política de las imágenes. Santiago de Chile, Ediciones Metales Pesados, 2017, pp. 39-68. Impreso.

Fall, Yoro. Historiografía, sociedades y conciencia histórica en África. México, D. F., 1990. Recuperado de https://www.jstor.org/ stable/j.ctv3f8nzj.3?seq=1\#metadata_info_tab_contents

Fischer-Lichte, Erika. Estética de lo performativo. Madrid, Abada Editores, 2014. Impreso. 
González Seguel, Evelyn. "Biografía KIMVN Teatro". Dramaturgias de la resistencia. Teatro documental, Kimvn marry xipan. Santiago de Chile, Pehuen, 2018, pp. 17-23 Impreso.

González Seguel, Paula. Dramaturgias de la resistencia. Teatro documental, Kimvn marry xipan. Santiago de Chile, Pehuen, 2018. Impreso.

González, Ernesto. “Grupo de Teatro Ad Mapu. Búsqueda de las raíces”. Revista Cauce, no. 102. 1987, p. 31.

Guerra, Lucía. "La ciudad ajena: subjetividades de origen mapuche en el espacio urbano". Cuadernos de Literatura, vol. 17, no. 33, enero-junio 2013, pp. 219-313. Recuperado de https://revistas.javeriana.edu.co/index.php/cualit/article/view/5600

Gutiérrez, Pía. "Revelaciones de archivo: representación y autorrepresentación del pueblo Mapuche en algunas manifestaciones teatrales chilenas a partir de 1940". Palimpsesto, vol. 8, no. 11, 2017, pp. 191-205.

Henríquez, Patricia. “Teatro maya: Rabinal Achí o Danza del Tun”. Revista Chilena de Literatura, no. 70, 2007, pp. 79-108.

Huenún, Jaime. Teatro mapuche para renacer. Kö fenten püllü, mapu fenten püllü. Espíritus del agua y de la tierra. Pichikeche ñi mapun azgelkantun. Teatro mapuche para niños. Santiago de Chile, Ministerio de Educación de Chile, 2013. Impreso.

Imilan, Walter. Experiencia warriache: espacios, performances e identidades mapuche en Santiago. Santiago de Chile, Ediciones Universidad Alberto Hurtado, 2014. Recuperado de http:// repositorio.uchile.cl/bitstream/handle/2250/132874/Experiencia\%20warriache.espacios\%2c\%20performances\%20. pdf? sequence $=1$ \&isAllowed $=\mathrm{y}$

Levil, Rodrigo. "Sociedad Mapuche Contemporánea". i...Escucha Winka...! Cuatro Ensayos de Historia Nacional Mapuche y un epílogo sobre el futuro. José Millalén, Pablo Marimán, Sergio Caniuqueo y Rodrigo Levil. Santiago de Chile, LOM ediciones, 2006, pp. 219-252. Impreso.

Mansilla, Pablo e Imilán, Walter. "Colonialidad del poder, desarrollo urbano y desposesión mapuche: urbanización de tierras mapuche en la Araucanía chilena". Revista Electrónica de Geografía y Ciencias Sociales, vol. 24, no. 630, 2020, pp. 1-23.

Martínez Neira, Cristian. “Transición a la democracia, militancia y proyecto étnico. La fundación de la organización mapuche Con- 
sejo de Todas las Tierras (1978-1990)". Estudios Sociológicos, vol. 27, no. 80, 2009, pp. 595-618.

Mazzotti, J. A. y U. J. Zeballos Aguilar (Coords.). "Sobre la heterogeneidad literaria y cultural de América Latina”. Asedios a la heterogeneidad cultural. Libro de homenaje a Antonio Cornejo Polar. Filadelfia, Asociación Internacional de Peruanistas, 1996, pp. 21-36.

McAuley, Gay. "Espacio y performance". Acta Poética, no. 24, 2003, pp. 7191. Recuperado de https://revistas-filologicas.unam.mx/actapoetica/index.php/ap/article/view/98. 17de marzo de 2020.

Mege, Pedro. "Los símbolos constrictores: una etnoestética de las fajas femeninas mapuches". Boletín del Museo Chileno de Arte Precolombino, no. 2, 1987, pp. 89-108.

Memoria chilena. "Danza mapuche". Memoria chilena, 2018. Recuperado de http://www.memoriachilena.cl/602/w3-article-92448.html

Menard, André. Manuel Aburto Panguilef. De la República Indígena al sionismo mapuche. Nuke Mapuförlaget, 2003. Impreso. Morris Von Bennewitz, Raúl y Juan Carlos Gedda. Platería mapuche. Santiago de Chile, Editorial Kactus, 1992. Impreso.

Núñez-Regueiro, Paz y María Filomena Guerra. "Los aros de plata de Patagonia septentrional: Aportes de la colección Henry de la Vaulx (1896) sobre forma, tecnología y metalurgia". Chungará, Revista de Antropología Chilena, vol. 48, no. 2, 2016, pp. 331-345.

Pelhan, Peggy. "La ontología de performance: representación sin reproducción". Unmarked. The politics of performance, 1993. Recuperado de http://performancelogia.blogspot. com/2007/05/la-ontologa-de-performance.html

Pereira Salas, Eugenio. Historia del teatro en Chile. Desde sus orígenes hasta la muerte de Juan Casacuberta. Santiago de Chile, Ediciones de la Universidad de Chile, 1974. Impreso.

Pradenas, Luis. Teatro en Chile. Huellas y trayectorias. Siglos XVI-XX. Santiago de Chile, LOM ediciones, 2009. Impreso.

Ruiz, Carlos. "La estructura ancestral de los mapuches: Las identidades territoriales, los longko y los Consejos a través del tiempo". Centro Mapuche de Estudio y Acción, 2003. Recuperado de https://www.folkloretradiciones.com.ar/literatura/Estructura\%20Ancestral\%20Mapuches.pdf 
Sarrazac, Jean Pierre. Léxico del drama moderno y contemporáneo. México, D. F., Toma, Ediciones y Producciones Escénicas y Cinematográficas, Paso de Gato, 2013. Impreso.

Segato, Rita. La nación y sus otros. Raza, etnicidad y diversidad religiosa en tiempos de Políticas de la Identidad. Buenos Aires, Prometeo Libros, 2007. Impreso.

Szondi, Peter. Teoría del drama moderno (1880-1950). Tentativa sobre lo trágico. Madrid, Editorial Dykinson, 2011. Impreso.

Taylor, Diana. El archivo y el repertorio, La memoria cultural performática en las Américas. Santiago, Ediciones Universidad Alberto Hurtado, 2015. Impreso.

Trastoy, Beatriz. "La dramaturgia autobiográfica en el teatro argentino contemporáneo". Archivo Artea, 2008. Recuperado de https://es.scribd.com/document/447086133/TRASTOY-Ladramaturgia-autobiografica-pdf

Villegas, Juan. Para la interpretación del teatro como construcción visual. Irvine, California, 2014. Impreso.

Zelada Arenas, Rodolfo y Fernando Espósito Galarce. "Rugosidades en el espacio mapuche: significados en la construcción de lugar". TRIADES, vol. 7, no. 2, 2018. Recuperado de https:// triades.emnuvens.com.br/triades/article/view/148. 17 de marzo de 2020. 